\title{
Condition monitoring of TPU/UPM Fiat tractors using ICP and OES techniques
}

Habib Imam Ahmad a, Desa Ahmad b*, Samsuzana Abd Aziz b, Muhamad Razif Mahadi b

aDepartment of Agricultural and Environmental Engineering, Faculty of Engineering, Bayero University, Kano, Nigeria.

${ }^{b}$ Department of Biological and Agricultural Engineering, Faculty of Engineering, Universiti Putra Malaysia, 43400 UPM, Serdang, Selangor, Malaysia

\section{ARTICLE HISTORY}

\section{Abstract}

The use of agricultural tractors for various operations within a day calls for adoption of condition monitoring techniques in maintenance management strategies especially regarding engine lubricating oil change interval and predicting components replacement time before premature failure. Six Fiat tractors from TPU/UPM were monitored over three oil change intervals and oil samples taken for analysis using inductively coupled plasma and optical emission spectroscopy (ICP \& OES). Twenty-three elements including wearing elements from engine, additive elements from oil manufacturers, and contaminating elements from the environment were determined from 39 samples collected. Results indicated significant differences for 15 elements $(\mathrm{Al}, \mathrm{B}, \mathrm{Ca}, \mathrm{Cr}, \mathrm{Cu}, \mathrm{Pb}, \mathrm{Mg}, \mathrm{Mo}, \mathrm{P}, \mathrm{Ti}, \mathrm{V}, \mathrm{Zn}, \mathrm{Si}, \mathrm{K}$, and $\mathrm{Na}$ ) belonging to wear, additive, and contaminating sources. This necessitated the use of condition monitoring for individual tractors instead of the general rule of preventive maintenance or even breakdown maintenance performed after the occurrence of failure.

\section{Introduction}

Agricultural tractors performing various operations within a day and in situations with non-homogenous load profiles such as soil contacting tasks need constant monitoring for proper maintenance. Condition monitoring as part of predictive maintenance is replacing breakdown and preventive methods, being more cost effective and facilitating hitch-free operations devoid of downtime (Stephen, 2004). The use of condition monitoring and diagnostic engineering management (COMADEM) has resulted in great financial savings for both large and small vehicles (Kaleli \& Yildirim, 2008; Davies, 1998). Other benefits associated with effective engine lubricating oil analysis have been reported (Ahmad et al., 2012; Kumar et al., 2005).

Lubricating oil in internal combustion engines during its operation undergoes various environmental stresses and leads to thermo-oxidative degradation of its base stock. Initially the degradation rate is slow due to protective action of additives; however, the rate dramatically increases as soon as the additive package gets depleted. This is normally reflected in abrupt changes in the oils various physical and chemical properties, and also in the system performance indicating the end of oil's useful life.

The oil change periodicity is a function of many parameters including operating, material contact, and environmental conditions. This periodicity is recommended by the manufacturer with considerable safety factor (Kaleli \& Yildirim, 2008). Discarding oil before the end of its complete useful life is an unnecessary addition to variable cost.

Engine oil degrades in quality during its use and after certain period of time the oil needs to be changed depending upon its condition. So that oil deterioration is subdivided into two main categories:

- $\quad$ Ageing which causes physical and chemical changes to occur in the oil as a result of oxidation and nitration
(Rohan, 2014)

- $\quad$ Ageing related to adverse external conditions such as sand dust, dirt, fuel, water, blow-by gases, and wear particles being introduced into the oil (Kumar et al., 2005: Kaleli \& Yavasliol, 1997).

High levels of wear particles give advance warning of possible machinery malfunction, allowing early remedial action to be taken. Where analytical results suggest no undue wearing is taking place, the operator may extend the interval between maintenance services, and the life of the oil change (Figure 1).

The common factors that influence the concentration of wear debris and contaminants in an oil sample are:

- the type of equipment

- the environment in which it is working

- the job that it is doing

- the skill of the operator

- the length of time that the oil has been in use

- oil consumption

Because of these factors, each piece of equipment must be treated on its own merits. It is far more beneficial to assess the wellbeing of a machine or lubricant on the basis of a trend analysis.

Wear limits do, however, have their uses (Table 1). If a diagnosis is to be made on the health of a component based on oil analysis and a trend is to be used, then this requires at least three samples to establish that trend. Tractors as very expensive equipment, and usually associated with risky operations, used to be studied under investigative approach with small sample sizes rather than experimental (Davies, 1998).

Correlating cumulative hours of work with elements concentration after change of lubricating oil could assist in predicting appropriate components/oil change periods (Ahmad, 


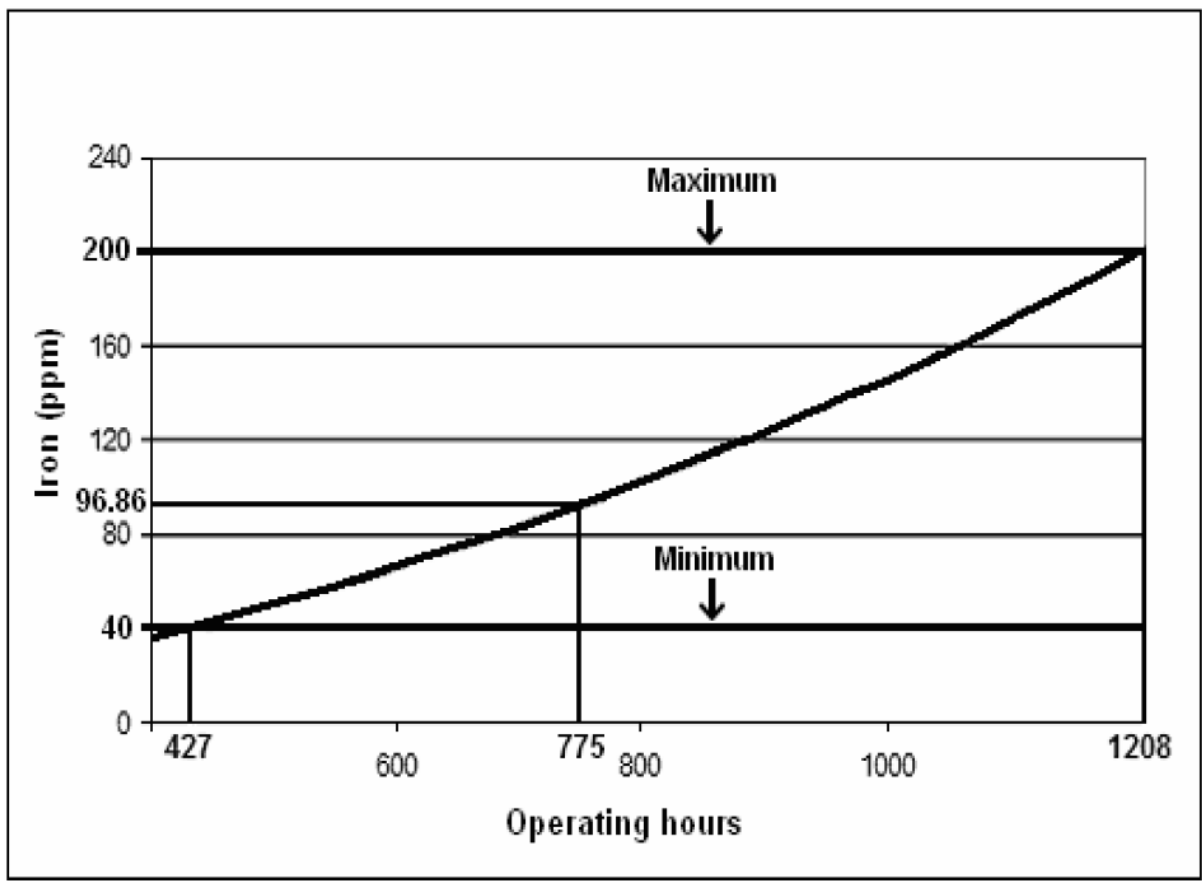

Figure 1. Extrapolation analysis result and limit values of Iron (Fe) (Kaleli \& Yildirim, 2008)

2020; Kaleli \& Yildirim, 2008). However, knowing the details of time segments give more insight of the work characteristics being performed and operational/environmental factors prevailing. Anytime the lubricating oil elements (wear, additive, and contaminating) are beyond tolerable limits, appropriate action (s) should be taken (Figure 2) as analogous to human beings need for the rest room.

Table 1. Maximum concentration limits for different elements of wear in engines (Kaleli \& Khorramian, 1998)

\begin{tabular}{ll}
\hline Metal & Content $(\mathrm{ppm})$ \\
\hline $\mathrm{Pb}$ & $5-40$ \\
$\mathrm{Si}$ & $10-20$ \\
$\mathrm{Fe}$ & $40-200$ \\
$\mathrm{Cr}$ & 30 \\
$\mathrm{Al}$ & $15-40$ \\
$\mathrm{Cu}$ & $5-40$ \\
$\mathrm{Sn}$ & $5-15$ \\
$\mathrm{Ag}$ & $5-10$ \\
\hline
\end{tabular}

Lubricants are the life blood of oil wetted machinery. As an important element of predictive maintenance technologies, inservice oil analysis can provide trace information about machine wear condition, lubricant contamination as well as lubricant condition (Figure 2). Reliability engineers and maintenance professionals can make maintenance decisions based on the oil analysis results. The immediate benefits of in-service oil analysis include avoiding oil mix up, contamination control, conditionbased maintenance, and failure analysis (Rohan, 2014).

Thus, tractor manufacturers should also provide means of recording time segments and not only cumulative hours with odometer. The tractor operators being knowledgeable enough can record various operations for each segment and reason(s) for each stoppage. This will produce the necessary information for full diagnosis of tractor fleet management as proposed in HTS-19 (Ahmad, 2020). HTS-19 is a tractor statistic analogous to global university ranking, corporate business all-share index, and football statistics.

The aim of this study was to quantify the variation of oil properties from TPU/UPM Fiat tractors using ICP \& OES technique as to show the need for flexible handling for each tractor against the conventional preventive maintenance approach for fleet of tractors in an organization.

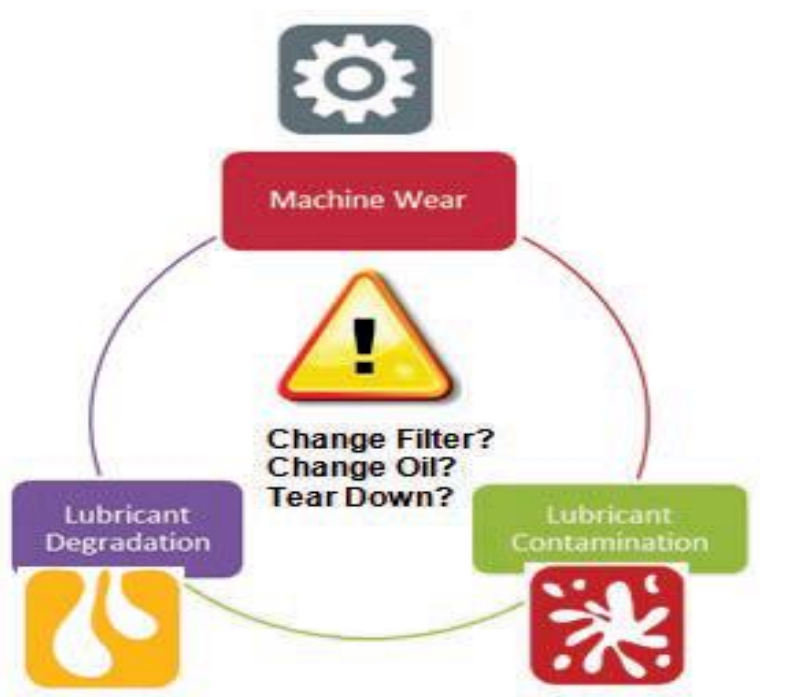

Figure 2. Information provided by in-service oil analysis (Rohan, 2014)

\section{Methodology}

\subsection{TPU Tractor services at UPM}

TPU is a unit within Universiti Putra Malaysia (UPM) concerned with tractors and heavy equipment operations. Any unit in UPM that needs tractor or heavy earth moving equipment service for research or civil works use to request for such assignment through formal means. Thus, all the tractors under TPU can be assigned to perform various operations as the need arises. Those assigned to locations outside TPU use to perform specific tasks but could be recalled or replaced depending on management decision. There is therefore the need to monitor the condition of these tractors through oil analysis as a condition monitoring strategy.

\subsection{Selection, and Use of Fiat Tractors by TPU}

The details of Fiat tractors selected, operation, and location are given in Table 2 . 
Table 2. Details, location and operations of TPU tractors used in the study

\begin{tabular}{lllll}
\hline S/No. & Tractor & \multicolumn{2}{l}{ Location } & Operation \\
\cline { 2 - 3 } & Reg. No. & Make & & \\
\hline 1 & BEL 5101 & Fiat 55-56 & Ladang Puchong & Trailing \\
2 & BDT 740 & Fiat 65-56 & Ladang Puchong & Mowing \\
3 & BCJ 568 & Fiat 666 & TPU & General \\
4 & BCJ 2629 & Fiat 666 & TPU & General \\
5 & BEL 8387 & Fiat 55-56 & Ladang Sepulo & Dairy/Transport \\
6 & WTH 2794 & Fiat 65-56 & Ladang Sepulo & Silage Making \\
\hline
\end{tabular}

\subsection{Collection of Samples from Fiat Tractors and analysis performed}

Engine lubricating oil were collected from the six tractors on weekly basis for three. Tractors that were not within any interval were omitted for oil sampling. A total of 39 samples including 3 as control and those for oil properties were obtained and taken for analysis. Wear metals, additive elements, and contaminating elements were determined using ICP \& OES techniques. The general lubricating oil properties also determined on the 39 samples were as follow: viscosity, total base number, flash point, oxidation, nitration, water content, soot level, and diesel content.

\subsection{Sample preparation for element determination}

Containers (bottles, vials, etc) typically are soaked in $10 \%$ nitric acid overnight, and rinsed with de-ionized water for several times before use. Solution samples typically are acidified with nitric acid at a ratio of 1-5 mL of concentrated nitric acid to one litre of sample. Extra cautions need to be exercised in preventing contamination and preserving samples for some specific analyses.

\subsection{Theory of ICP\&OES Technique}

Any sample that can be dissolved or digested into an aqueous solution can be analysed with ICP \& OES technique (Eurofins, 2020).

The ICP \& OES has many benefits for the analysis of oils. The samples are simply diluted, in kerosene or other suitable solvent, and aspirated directly into the ICP \& OES. The ICP \& OES analysis is very fast, and gives accurate, precise results (Johnson, 2010).

\subsection{The analytical principle}

The analytical principle used in the ICP \& OES system is optical emission spectroscopy. A liquid sample is nebulized and

\section{Atomic Absorption}

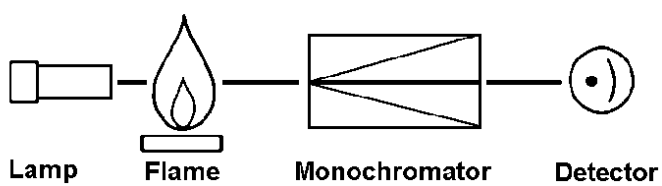

\section{Atomic Fluorescence}

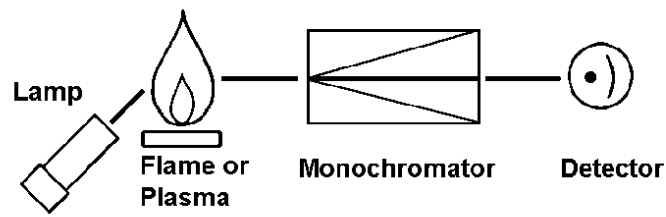

then vaporized within the argon plasma in same way as the Inductively Coupled Plasma-Mass Spectroscopy (ICP-MS). Unlike the Mass Spectroscopy however, the atoms and ions contained in the plasma vapour are excited into a state of radiated light photon emission. The radiation emitted is passed to the spectrometer optics, where it is dispersed into its spectral components. From the specific wavelengths emitted by each element, the most suitable line for the application is measured by means of a charge couple device (CDD). This instrument is capable of determining the concentrations of 40 to 70 elements simultaneously to very low detection limits (ppm to $\mathrm{ppb}$ ).

ICP \& OES provides the highest and lowest levels for 29 elements which include $\mathrm{Al}, \mathrm{As}, \mathrm{B}, \mathrm{Bi}, \mathrm{Ca}, \mathrm{Cd}, \mathrm{Co}, \mathrm{Cr}, \mathrm{Cu}, \mathrm{Fe}, \mathrm{Li}, \mathrm{Mn}$, $\mathrm{Ni}, \mathrm{P}, \mathrm{Pb}, \mathrm{Se}, \mathrm{Sr}, \mathrm{Ti}, \mathrm{Tl}, \mathrm{V}$, and $\mathrm{Zn}$ (Wearcheck, 2020). The ICP \& OES technology allows for very low-level determination and uncertainty of many elements. Other strengths of ICP \& OES technique include:

- High sensitivity

- Large dynamic ranges from detection limit to the maximum working concentration (order of 8 compared to 2 in graphite furnace atomic absorption)

- Short elemental concentration determination time

- The ability to measure individual isotopes

The ICP \& OES is most moderate in terms of cost versus performance consideration when compared to flame atomic absorption spectroscopy (AAS) and ICP \& OES-MS and precision of its results confirmed by ICP \& OES-MS. The superiority of ICP \& OES over AAS has been documented (Ahmad et al., 2014) The four different arrangements used in ICP are shown in Figure 3.

\subsection{Specification and operating parameters of ICP\&OES machine}

The specification and operational parameters of the ICP \& OES instrument used by in determining the lubricating oil elements are given Table 3.

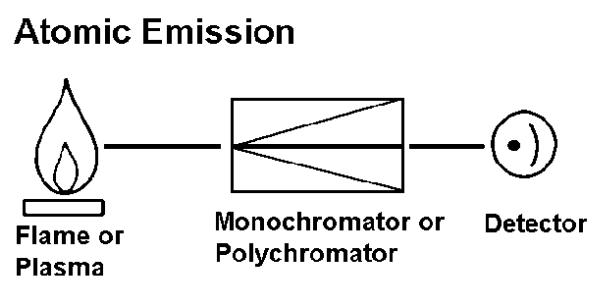

\section{Atomic Mass Spectrometry}

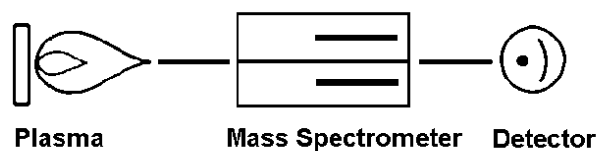

Figure 3. Four instrumental arrangement techniques used to detect atoms or ions using ICP (Boss \& Fredeen, 1997) 
Table 3. ICP-OES Instrument specifications and operating parameters

\begin{tabular}{ll}
\hline ICP-OES Instrument specifications & Operating parameters \\
\hline ICP-OES & TJA IRIS Advantage ICP-OES \\
Plasma forward power & $1150 \mathrm{~W}$ \\
Plasma height & Yttrium bullet halfway between coil top and torch top \\
Coolant gas flow rate & Instrument default \\
Auxiliary gas flow rate & Low \\
Nebulizer Glass Expansion & Sea Spray \\
Nebulizer pressure & $26 \mathrm{psi}$ \\
Spray chamber & Glass Expansion Tracey Cyclonic \\
Pump rate & $100 \mathrm{rpm}$ \\
Tubing & Orange-orange \\
Sample uptake rate & $1.2 \mathrm{~mL} /$ min \\
Sample uptake time & $30 \mathrm{~s}$ \\
Acquisition & $30 \mathrm{~s}$ Low wave length range, $10 \mathrm{~s}$ high wave length range. Twice. \\
Wash solution & De-ionized water or very diluted nitric acid $(<1 \% \mathrm{v} / \mathrm{v})$ \\
Wash time & $15 \mathrm{~s}$ \\
\hline
\end{tabular}

\section{Result and discussion}

\subsection{General oil properties results}

The results of the general oil properties are given Figures 34. Figure 3 shows the variation of kinematic viscosity for the six tractors samples over the period studied. Contamination from soot or fuel usually causes degradation of viscosity in diesel engines (Rohan, 2014). Tractor number one (Figure 4) recorded change of kinematic viscosity from 13.65 to $14.10 \mathrm{cSt}$ at $100{ }^{\circ} \mathrm{C}$. The ASTM D7042-04 standard recommended working viscosities to be between $272-368 \mathrm{cSt}$ at $40^{\circ} \mathrm{C}$. There is a widely held view that in applications, oil should be changed when its TBN falls to 50 per cent of the original level (ASTM D445/89). All the six tractors recorded less than $50 \%$ reduction of TBN during the tests.

It is found that all of the general oil properties data determined up to the end of the test duration are within acceptable levels. This kind of acceptance level was obtained in a 390 hours study for diesel engines in Turkey (Kaleli \& Yildirim, 2008).

\section{Sources of Elements and Allowable limits}

\subsection{Wear elements}

The wear elements with significant differences from the TPU/UPM Fiat tractors are $\mathrm{Pb}, \mathrm{Al}, \mathrm{Cr}, \mathrm{Cu}, \mathrm{Mo}$, and Ti. Only Fe, Ni and $\mathrm{Sn}$ were not concentrations not significantly different between the 6 tractors (Table 4). From Table 1, it can be deduced that all the 6 wearing elements concentrations in Table 4 are within limits.

\subsection{Additive elements}

The additive elements from TPU/UPM Fiat tractors are shown in Table 4. All the additive elements concentrations are within tolerable limits when with ASTM D6595-00 standards (Rohan, 2014).

\subsection{Contaminating elements}

The contaminant elements from TPU/UPM Fiat tractors are shown in Table 4. All the four contaminant elements have concentrations that are significantly different between the six tractors studied. However, none of them has concentration above the warning limit (Rohan, 2014).

\section{Conclusions}

This study introduces condition monitoring as a better technique of carrying out maintenance procedures for tractors. It is concluded that this strategy will greatly reduce cost of maintaining tractors as the results indicated all indicators within tolerable limits.

\section{Recommendation}

It is hereby recommended that TPU management should adopt oil analysis as means of determining appropriate engine lubrication oil change interval for individual tractors instead of the fixed hours or days used before.

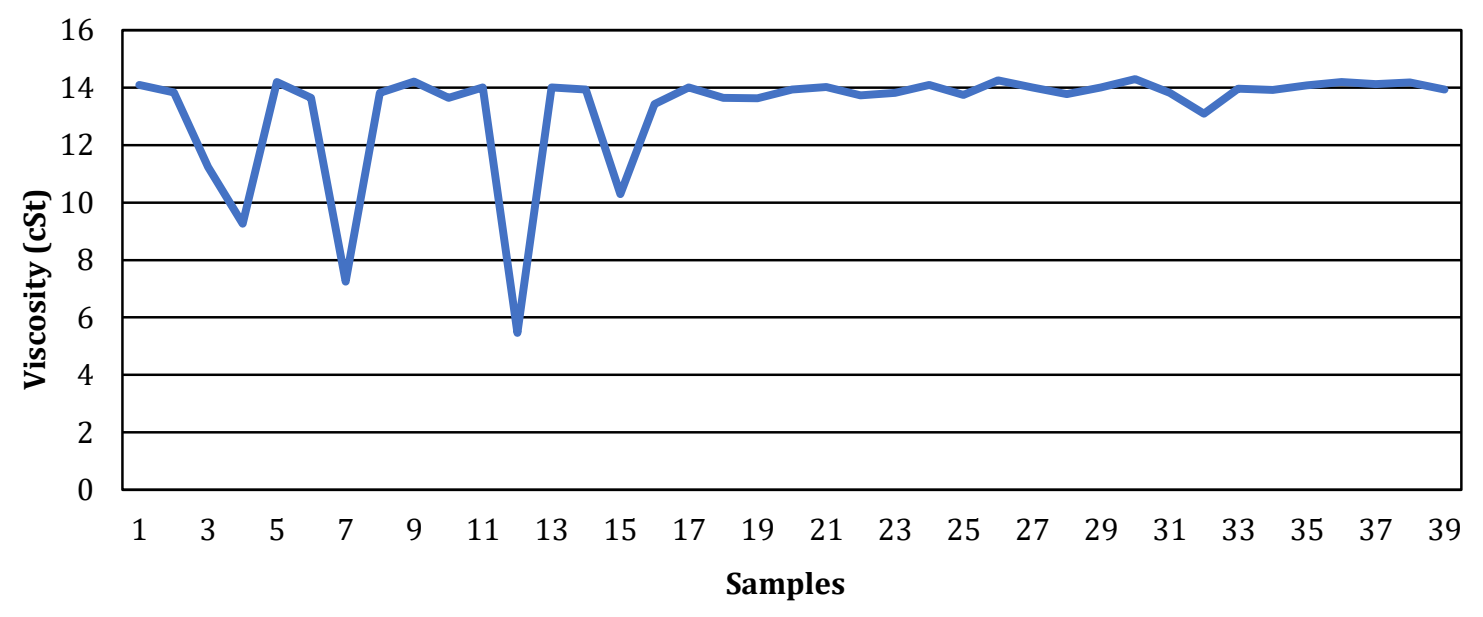

Figure 3. Variation of kinetic viscosity of the 39 samples 


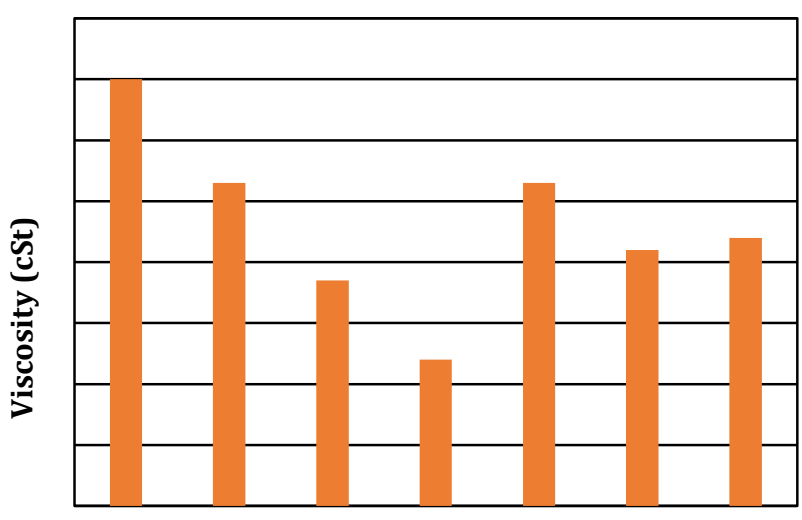

Samples for tractor 1

Figure 4. Variation of kinematic viscosity for tractor No. 1

Table 4. Elements determined from the TPU tractors (Elements with * have concentrations with significant differences between the tractors)

\begin{tabular}{llll}
\hline S/No. & Element & Category & Mean Conc. (PPM) \\
\hline 1 & $\mathrm{Fe}$ & Wear & 4.566 \\
2 & ${ }^{*} \mathrm{~Pb}$ & Wear & 0.953 \\
3 & ${ }^{*} \mathrm{Al}$ & Wear & -0.219 \\
4 & ${ }^{*} \mathrm{Cr}$ & Wear & 0.454 \\
5 & ${ }^{*} \mathrm{Cu}$ & Wear & 0.589 \\
6 & ${ }^{*} \mathrm{Mo}$ & Wear & 0.194 \\
7 & $\mathrm{Ni}$ & Wear & 0.472 \\
8 & ${ }^{* T i}$ & Wear & 0.117 \\
9 & $\mathrm{Ag}$ & Wear & -0.004 \\
10 & $\mathrm{Sn}$ & Wear & -0.050 \\
11 & $\mathrm{Ba}$ & Additive & 0.015 \\
12 & ${ }^{*} \mathrm{~B}$ & Additive & 1.116 \\
13 & ${ }^{*} \mathrm{Ca}$ & Additive & 2522.8 \\
14 & ${ }^{*} \mathrm{Mg}$ & Additive & 10.770 \\
15 & $* \mathrm{P}$ & Additive & 581.87 \\
16 & $* \mathrm{Zn}$ & Additive & 683.43 \\
17 & $* \mathrm{~V}$ & Contaminant & -0.051 \\
18 & $* \mathrm{Si}$ & Contaminant & 4.288 \\
19 & $* \mathrm{~K}$ & Contaminant & 1.648 \\
20 & $* \mathrm{Na}$ & Contaminant & 4.428 \\
21 & $\mathrm{Mn}$ & & -0.046 \\
22 & $\mathrm{Cd}$ & & 0.189 \\
23 & $\mathrm{Co}$ & & - \\
\hline
\end{tabular}

\section{Acknowledgment}

The authors wish to acknowledge the assistance received in getting this work completed. TPU/UPM provided the tractors used in collecting the oil samples within the period of the study and also the technical staff (including Late Ahmad-my AYA) gave maximum cooperation needed. The UPM research committee supplied the lubricating oil/filters used and paid for analyzing the oil samples. Dr Tukur Dayyabu Abdulkadir assisted with SAS analysis runs.

\section{Author contributions}

Habib Imam Ahmad: Conceptualization, methodology, data collection and drafting the manuscript. Desa Ahmad: Review and editing the manuscript, supervision and project administration. Samsuzana Abd Aziz: Review and editing the manuscript and cosupervision. Muhammad Razif Mahadi: Review and editing the manuscript and co-supervision.

\section{Conflict of interests}

The authors declare that they have no known competing financial interests or personal relationships that could have appeared to influence the work reported in this manuscript.

\section{References}

Ahmad, H. I., Suleiman, M. L., Ahmad, D., \& Yusuf, D. D. (2012). Determination of wear elements in steyr ursus tractor lubricating oil using atomic absorption spectroscopy (AAS). International Conference on Agricultural and Food Engineering for Life (Cafei 2012) 26-28 November 2012, Pgs. 85-96.

Ahmad, H. I., Ahmad, D., Suleiman, M. L., \& Yusuf, D. D. (2014). Determination of wear elements in steyr ursus tractor lubricating oil: comparison between AAS and ICP \& OES. Journal of Agricultural Engineering and Technology (JAET), Nigerian Institution of Agricultural Engineers (NIAE). Vol. 22: 19-28.

Ahmad, H. I. (2020). Strategies for increasing availability of tractors in Kano State of Nigeria. Unpublished Report, Universiti Putra Malaysia.

ASTM D7042-04. Standard test method for dynamic viscosity and density of liquids by Stabinger viscometer (and the calculation of kinematic viscosity).

ASTM D6595-00. Standard Test method for determination of wear metals and contaminants in used lubricating oils or used hydraulic fluids by rotating disc electrode atomic emission spectrometry.

ASTM D445. Standard test method for kinematic viscosity of transparent and opaque liquids (and calculation of dynamic viscosity).

Boss, C. B., \& Fredeen, K. J. (1997). Concepts, Instrumentation, and Techniques in Inductively Coupled Plasma Optical Emission Spectroscopy. Perkin-Elmer Corporation, USA.

Eurofins (2020). Retrieved from https://www.eurofins.co.nz/, Accessed date: January 2020

Davies, A. (ed.) (1998). Handbook of Condition Monitoring: Techniques and Methodology. Systems Division, School of Engineering, University of Wales-Cardiff (UWC), P.0 Box 688, Queens Buildings, Newport Road, Cardiff, CF2 3TE, UK.

Johnson, J. M. F., Wilhelm, W. W., Karlen, D. L. et al. (2010). Nutrient removal as a function of corn stover cutting height and cob harvest. BioEnergy Research, 3, 342352. https://doi.org/10.1007/s12155-010-9093-3

Kaleli, H., \& Yildirim, E. (2008). Determination of Oil Drain Period in Naval Ship Diesel Engine. Tribology in industry, Volume 30, No. 3\&4, Pgs. 21-30.

Kaleli, H., \& Khorramian, B. (1998) "Used Oil Analysis and Study of Oil Drain Period in Gasoline Engine", SAE International, SAE Technical Paper Series 981448, pp. 91-104, Michigan, USA. https://doi.org/10.4271/981448

Kumar, S., Mishra, N., \& Mukherjee, P. (2005). Additives Depletion and Engine Oil Condition - a Case Study. Industrial Lubrication and Tribology, Emerald Group Publishing, Vol. 57, pp. 69-72, Jharkhand, India. https://doi.org/10.1108/00368790510583375

Rohan, A. (2014). Oil Analysis Handbook for Predictive Equipment Maintenance. Spectro Scientific.

Stephen, M. P. (2004). Productivity and Reliability-Based Maintenance Management. Prentice Hall Publishing.

Wearcheck (2020). Retrieved from http://www.wearcheck.co.za/, Accessed date: January 2020 